\title{
POU-domain factor Brn3a regulates both distinct and common programs of gene expression in the spinal and trigeminal sensory ganglia
}

\author{
S Raisa Eng, Iain M Dykes, Jason Lanier, Natalia Fedtsova and Eric E Turner*
}

Address: Department of Psychiatry, University of California, San Diego and VA San Diego Healthcare System, Gilman Drive, La Jolla, CA 920930603, USA

Email: S Raisa Eng - sreng@ucsd.edu; Iain M Dykes - idykes@ucsd.edu; Jason Lanier - jlanier@ucsd.edu; Natalia Fedtsova -nfedtsova@ucsd.edu; Eric E Turner* - eturner@ucsd.edu

* Corresponding author

Published: 19 January 2007

Neural Development 2007, 2:3 doi:10.1186/1749-8104-2-3
Received: 4 November 2006

Accepted: 19 January 2007

This article is available from: http://www.neuraldevelopment.com/content/2/1/3

(c) 2007 Eng et al; licensee BioMed Central Ltd.

This is an Open Access article distributed under the terms of the Creative Commons Attribution License (http://creativecommons.org/licenses/by/2.0), which permits unrestricted use, distribution, and reproduction in any medium, provided the original work is properly cited.

\begin{abstract}
Background: General somatic sensation is conveyed to the central nervous system at cranial levels by the trigeminal ganglion (TG), and at spinal levels by the dorsal root ganglia (DRG). Although these ganglia have similar functions, they have distinct embryological origins, in that both contain neurons originating from the neural crest, while only the TG includes cells derived from the placodal ectoderm.

Results: Here we use microarray analysis of El3.5 embryos to demonstrate that the developing DRG and TG have very similar overall patterns of gene expression. In mice lacking the POUdomain transcription factor Brn3a, the DRG and TG exhibit many common changes in gene expression, but a subset of Brn3a target genes show increased expression only in the TG. In the wild-type TG these Brn3a-repressed genes are silent, yet their promoter regions exhibit histone $\mathrm{H} 3$-acetylation levels similar to constitutively transcribed gene loci. This increased $\mathrm{H} 3$-acetylation is not observed in the DRG, suggesting that chromatin modifications play a role in cell-specific target gene regulation by Brn3a.

Conclusion: These results demonstrate that one developmental role of $\mathrm{Brn} 3 \mathrm{a}$ is to repress potential differences in gene expression between sensory neurons generated at different axial levels, and to regulate a convergent program of developmental gene expression, in which functionally similar populations of neurons are generated from different embryological substrates.
\end{abstract}

\section{Background}

The generation of cellular diversity in the developing vertebrate nervous system is one of the most complex problems in biology, and a large number of transcription factors have been identified that orchestrate neurodevelopment and regulate the molecular identity of neurons. Perhaps the best-studied systems for the establishment of neuronal phenotypes in vertebrates are the primary input (sensory) and output (motor) pathways of the peripheral sensory ganglia, spinal cord, and brainstem. In these areas, several key transcriptional regulators have been identified, many of which are members of the basic-helixloop-helix (bHLH) and homeodomain transcription factor classes $[1,2]$. 
The peripheral sensory nervous system is organized anatomically according to the nature of the external information reported to the central nervous system (CNS). The sensory modalities of pain, touch, temperature and proprioception are transduced by sensory neurons innervating the skin and musculoskeletal structures, and are referred to as general somatic sensation. Peripheral sensory neurons also convey the senses of taste and hearing, and visceral sensation, which reports the state of the internal organs. At spinal levels, general somatic sensation is conveyed by the dorsal root or spinal ganglia (DRG), while in the anterior head and face, these sensory modalities are mediated by the trigeminal ganglion (TG).

Surprisingly, in spite of the similar functions of the DRG and TG, these ganglia have rather different embryological origins. The DRG are formed entirely from spinal neural crest. In contrast, the TG is formed in part from the ophthalmic and maxillo-mandibular placodes originating in the surface ectoderm, as well as cranial neural crest cells derived from rhombomere 2, which migrate and condense to form the ganglion $[3,4]$. The trigeminal system also includes a population of sensory neurons that reside outside the anatomical ganglion, the mesencephalic trigeminal (mesV), the exact origin of which is still somewhat controversial $[5,6]$. The developmental mechanisms that lead to the differentiation of functionally similar populations of neurons from these different embryological sources are not well understood.

Transcriptional regulators of sensory development may be broadly divided into early factors that are essential for neurogenesis, pan-sensory factors that begin to be expressed around the time of cell-cycle exit, and late factors that characterize specific sensory subtypes. In mice, the proneural bHLH factors Ngn1 and Ngn2 are expressed transiently from embryonic day 8.5 in cranial sensory precursors and have been shown to have a crucial role in neurogenesis [7-9]. Around the time of ganglion condensation and cell cycle exit, beginning at E9.5-10.5, nearly all sensory neurons at both spinal and cranial levels co-express the homeodomain transcription factors Brn3a and Islet $1[1,10]$. Later in development, factors associated with the development of specific sensory subtypes include the runt family factors Runx1 and Runx3, the variant homeodomain protein Prrxl1/DRG11, and the Ets family member Etv1/Er81 [1,11-15].

Studies of Brn3a knockout mice have shown that this factor is required for correct axon growth, target innervation, and survival of TG and DRG neurons [16-19]. Microarray studies of the developing TG of Brn3a null mice have shown that Brn3a is required for a complex program of sensory gene expression [20]. In the present study, we examine the role of Brn3a in sensory neurogenesis at trun- cal and cranial levels. In normal mice, the developing DRG and TG have very similar patterns of global gene expression. The loss of Brn3a expression in the developing DRG leads to marked changes in the expression of specific neurotransmitters, receptors, developmental regulators, mediators of signal transduction, and transcription factors. Many of these changes are conserved between the TG and DRG of Brn3a knockout mice, but certain transcripts are markedly increased only in the cranial ganglia. The promoter regions of these normally silent but differentially regulated genes are hyperacetylated only in the TG, which may indicate a latent state of 'expressability' that can differ between spinal and cranial levels. Thus, a key developmental role of Brn3a may be to repress potential differences in gene expression between developing DRG and TG neurons, and thus promote the generation of functionally similar populations of neurons from different embryological sources.

\section{Results \\ Global gene expression is highly conserved in sensory neurons from different axial levels}

To begin to compare the molecular program of sensory neuron development at spinal and cranial levels, we performed global analysis of gene expression in the developing DRG and TG. E13.5 was chosen for this comparison because, at this stage, most of the neurons of the DRG and TG have exited the cell cycle and have begun to express definitive markers of neurogenesis. Because sensory neurons have conserved functions at spinal and cranial levels, we hypothesized that the global pattern of gene expression in the DRG would be much more similar to the TG than to other neural tissues. Figure 1 illustrates a comparison of gene expression in the DRG to a replicate analysis from the same tissue, to the TG, and to the embryonic neocortex. These results show a high degree of overall similarity in gene expression between the sensory ganglia from different axial levels, and confirm that there is much greater divergence between the patterns of gene expression in the DRG and the developing cerebral cortex.

Overall, only a very small fraction of the approximately 44,000 transcripts assayed by the array showed profound differences in expression between the DRG and TG (Table 1). Significantly more transcripts were uniquely expressed in the DRG, and seven out of ten of the transcripts with the highest relative expression in the DRG encoded Hox transcription factors, an expected finding given the axial restriction of Hox expression. Several of the other differentially expressed genes revealed in the microarray analysis could be validated by in situ hybridization (see additional file 1), although some differences appear to represent anomalous findings that may be related to factors such as high expression in peripheral glia (Ednrb, Sostdc1). 

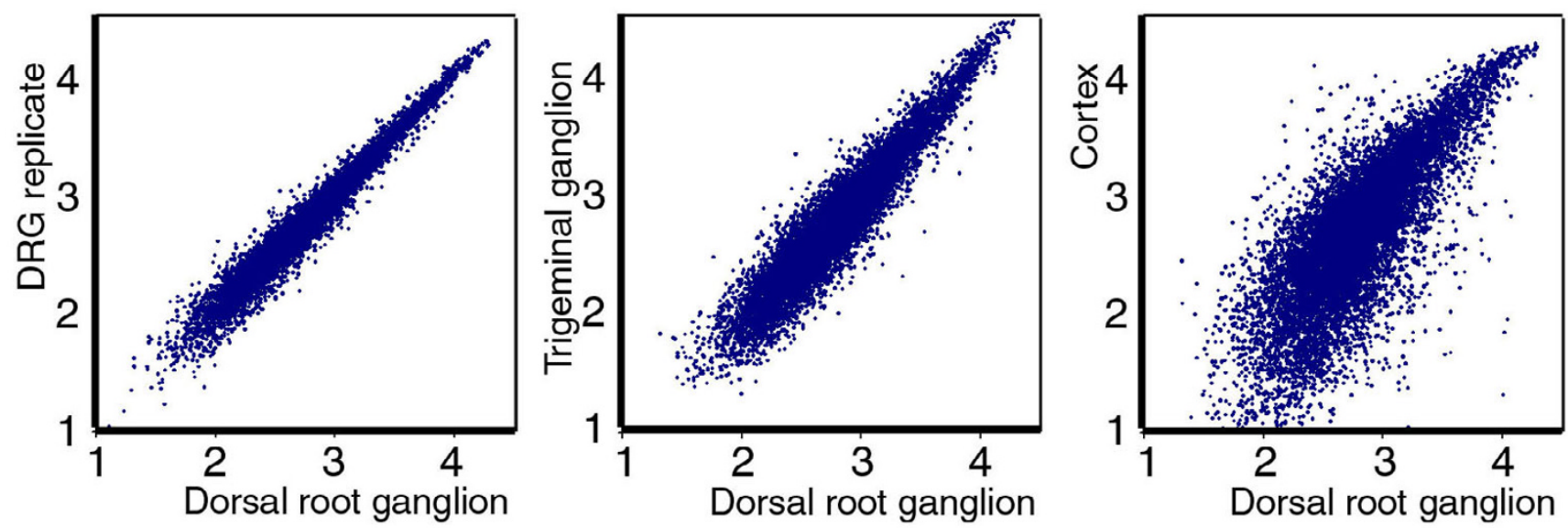

Figure I

Analysis of global gene expression in embryonic neural tissue. Analysis of global gene expression was performed using EI3.5 DRG, EI3.5 TG and EI6.5 cerebral cortex samples. Only probe sets on the Affymetrix 430A array are shown, and transcripts with 'absent' calls in all three samples were excluded from the analysis. (a) Plot of DRG expression versus a replicate DRG assay closely approximates a diagonal line indicating equal expression in the two samples. (b) Plot of DRG expression versus the TG indicates very similar global gene expression in the two samples, with few points lying far from the diagonal. (c) Plot of DRG expression versus the embryonic cerebral cortex indicates a large number of transcripts that are differentially expressed between the two samples. Axis is graduated in $\log 10$ of scaled signal.

Aside from the Hox factors, the transcript with the greatest relative expression in the DRG was Etv1, an Ets-family transcription factor expressed in 1a muscle spindle afferents $[13,21]$. Immunofluorescence for Etv1 expression in the E13.5 DRG confirmed expression in sensory neurons of large and intermediate size, whilst expression was entirely absent in the TG at this stage (Figure 2a, b). In contrast, expression of Runx3, an earlier and more general marker of proprioceptive neurons $[13,14]$, was noted in both the DRG and TG at E13.5 (Figure 2c, d).

By E16.5, Etv1 expression could be detected in some neurons of the TG, as well as the DRG. In the DRG, one population of Etv1-expressing neurons displayed large soma and nuclei consistent with 1a proprioceptors. However, in the TG nearly all of the Etv1-expressing neurons were of intermediate size, and large Etv1-positive neurons consistent with 1a proprioceptors were rare. In both the DRG and the TG, this intermediate-sized and later-developing population of Etv1-expressing sensory neurons could be further distinguished from the 1a proprioceptors by the coexpression of Islet2 (Figure 2e, f).

One distinguishing feature of the TG is that a subset of neurons that are functionally part of the trigeminal system, the mesV, is located within the CNS. Examination of the mesV in late gestation revealed large sensory neurons positive for Etv1. These neurons co-expressed a tauLacZ transgene integrated into the Brn3a locus, and Brn3a is a known marker of the mesencephalic trigeminal [6]. The position of these neurons in the caudal midbrain is consistent with the role of some of these neurons as muscle spindle afferents for the muscles of mastication [22]. Thus, the exclusive expression of Etv1 in the DRG but not the TG at E13.5 appears to result from a population of Etv1 ${ }^{+}$, Islet2- proprioceptive neurons that are present in the DRG but are largely restricted to the mesV at the cranial level.

\section{Brn3a regulates multiple downstream targets in the DRG}

To understand the developmental programs regulated by Brn3a at spinal versus cranial levels, we next analyzed global gene expression in E13.5 DRG from Brn3a mutant embryos and wild-type controls. Tables 2 and 3 summarize the transcripts most increased and decreased at E13.5 in the DRG of Brn3a knockout mice, and a more complete list appears in additional file 2. In situ hybridization and immunofluorescence were used to verify altered expression of several of the target genes (Figures 3 and 4), with an emphasis on newly identified Brn3a targets and genes for which expression has not been previously described in the sensory ganglia.

Most of the Brn3a-regulated genes of known function have specific roles in neurotransmission, axonogenesis/ synaptogenesis, signal transduction, regulation of developmental pathways, or transcription. Among mediators of neurotransmission, multiple glutamate receptors (Gria3, Gria4, Grik1), a GABA transporter (Slc6a1), a serotonin receptor (Htr3a) and the neuropeptide somato- 
Table I: Transcripts differentially expressed in the DRG and TG

\begin{tabular}{|c|c|c|c|}
\hline Transcript & Symbol & Class & Fold \\
\hline \multicolumn{4}{|l|}{ Greater expression in the DRG } \\
\hline Homeobox B3 & $\mathrm{Hoxb}^{2}$ & $\mathrm{TX}$ & $(90.4)$ \\
\hline Homeobox A9 & Hoxa9 & TX & $(90.2)$ \\
\hline Homeobox A5 & Hoxa52 & $\mathrm{TX}$ & (44.2) \\
\hline Etvl; ER8I & Etv $I^{3}$ & TX & $(40.2)$ \\
\hline Homeobox $\mathrm{C} 8$ & Hoxc8 ${ }^{2}$ & $\mathrm{TX}$ & (38.4) \\
\hline Homeobox B6 & Hoxb6 & $\mathrm{TX}$ & $(27.6)$ \\
\hline Hoxd4 & Hoxd4 & TX & $(16.6)$ \\
\hline Follistatin & $\mathrm{Fst}^{2}$ & Dev & $(12.9)$ \\
\hline Leucine-rich repeat-containing $\mathrm{G}$ protein-coupled receptor 6 & Lgr6 & Other & $(\mathrm{l} 1.8)$ \\
\hline Receptor (calcitonin) activity modifying protein 2 & $\operatorname{Ramp} 2^{3}$ & ST & 10.9 \\
\hline $\mathrm{Ca}^{+}$channel, $\mathrm{L}$ type, alpha IC subunit & Cacnalc & NT & 9.2 \\
\hline Homeobox B8 & Hoxb8 & $\mathrm{TX}$ & $(9.1)$ \\
\hline BTB and CNC homology 2 & Bach2 & $\mathrm{TX}$ & $(8.8)$ \\
\hline Sclerostin domain containing I & Sostdcl & Dev & 8.5 \\
\hline Laminin, alpha 2 & Lama2 & Other & $(7.3)$ \\
\hline \multicolumn{4}{|l|}{ Selected } \\
\hline Purkinje cell protein 4 & Pсp4 & Unk & $(5.7)$ \\
\hline LIM domain binding 2 & $\mathrm{Ldb}^{2}$ & $\mathrm{TX}$ & 5.6 \\
\hline Zinc finger protein of the cerebellum I & Zicl2 ${ }^{2}$ & $\mathrm{TX}$ & 5.3 \\
\hline Gap junction membrane channel protein alpha I & $\left.\mathrm{Gja}\right|^{2}$ & NT & 5.1 \\
\hline Protein tyrosine phosphatase, receptor type, E & Ptpre $^{3}$ & ST & 5.0 \\
\hline Early B-cell factor I; OlfI & Ebfl & $\mathrm{TX}$ & 5.0 \\
\hline \multicolumn{4}{|l|}{ U74 array } \\
\hline Regulator of G-protein signaling 4 & RGS4 & NT & 6.1 \\
\hline Endothelin receptor type B & EDNRB & Other & 3.0 \\
\hline Anthrax toxin receptor 2 & Antxr2 & Unk & 3.0 \\
\hline \multicolumn{4}{|l|}{ Greater expression in the TG } \\
\hline Microfibrillar-associated protein 4 & Mfap4 & Unk & $(20.6)$ \\
\hline Lectin, galactose binding, soluble 7 & Lgals7 & $A X$ & $(11.3)$ \\
\hline MyoD family inhibitor & Mdfi & $\mathrm{TX}$ & $(9.6)$ \\
\hline Suppressor of cytokine signaling 3 & Socs $3^{2}$ & ST & (6.4) \\
\hline RNA imprinted and accumulated in nucleus & Rian & Unk & 6.1 \\
\hline Musashi homolog 2 & Msi2h & Other & 6.0 \\
\hline \multicolumn{4}{|l|}{ U74 array } \\
\hline Neuropeptide $Y$ receptor I & NpyRI & NT & 8.6 \\
\hline
\end{tabular}

The principal analysis was conducted with the murine 430 array, with selected results identified using the U74A+B array set added. All listed transcripts showed increased expression (change $p<0.005$ ) in two independent replicates. Fold values represent the ratio of the means of two determinations for each tissue. Fold changes in parentheses indicate an absent call, that is, below the statistically reliable limit of detection, in the lower expressing sample. Transcripts with expression levels less than $40 \%$ of the scaled mean are excluded. Superscript numerals represent the number of probe sets concordant for changed expression for a given gene. AX, axonogenesis; Dev, development; NT, neurotransmission; ST, signal transduction; Syn, synaptogenesis; TX, transcription; Unk, unknown. Greater expression in the DRG: confirmation of selected results by in situ hybridization and immunofluorescence appears in additional file I. Differential expression of Ramp2 could not be confirmed by ISH. Different levels of Zicl and follistatin appear to be due to high expression in the spinal cord adjacent to the DRG, rather than the DRG itself. Sostdcl and EDNRB showed increased DRG expression by ISH but in a pattern more characteristic of glial than neuronal expression, with signal concentrated in nerve roots. The expression of RGS4 in the developing sensory ganglia has been previously described [43], and its higher expression in the DRG at EI3.5 appears to be due to the dynamic developmental regulation of this gene, rather than a persisting difference in expression between the DRG and TG. Greater expression in the TG: in situ hybridization confirmed some changes (see additional file I). However, Mfap4 was widely expressed in embryonic tissues. Socs3 ISH exhibited relatively greater expression in the TG, but overall expression levels were low. Differential expression of the supressor of cytokine signaling Socs 3 in the TG and DRG has previously been noted [44].

statin are increased, while a GABA receptor (Gabra2) and neuropeptides with specific sensory roles (Galanin, Adcyap1/PACAP) are decreased. Also reduced is latexin, a secreted carboxypepidase inhibitor with a role in nociception [23].
Profound changes were also observed in genes that encode known or potential mediators of sensory neurogenesis, and axon growth or guidance. Increased transcripts in this class included the cell adhesion molecule Chl1, which has a known role in the growth of cortical 

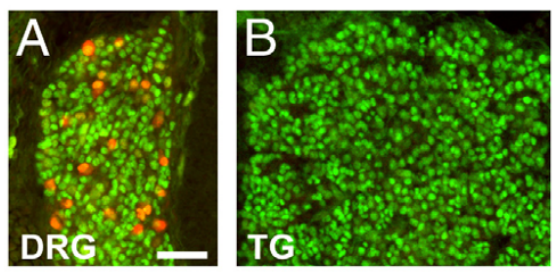

\section{Etv1}
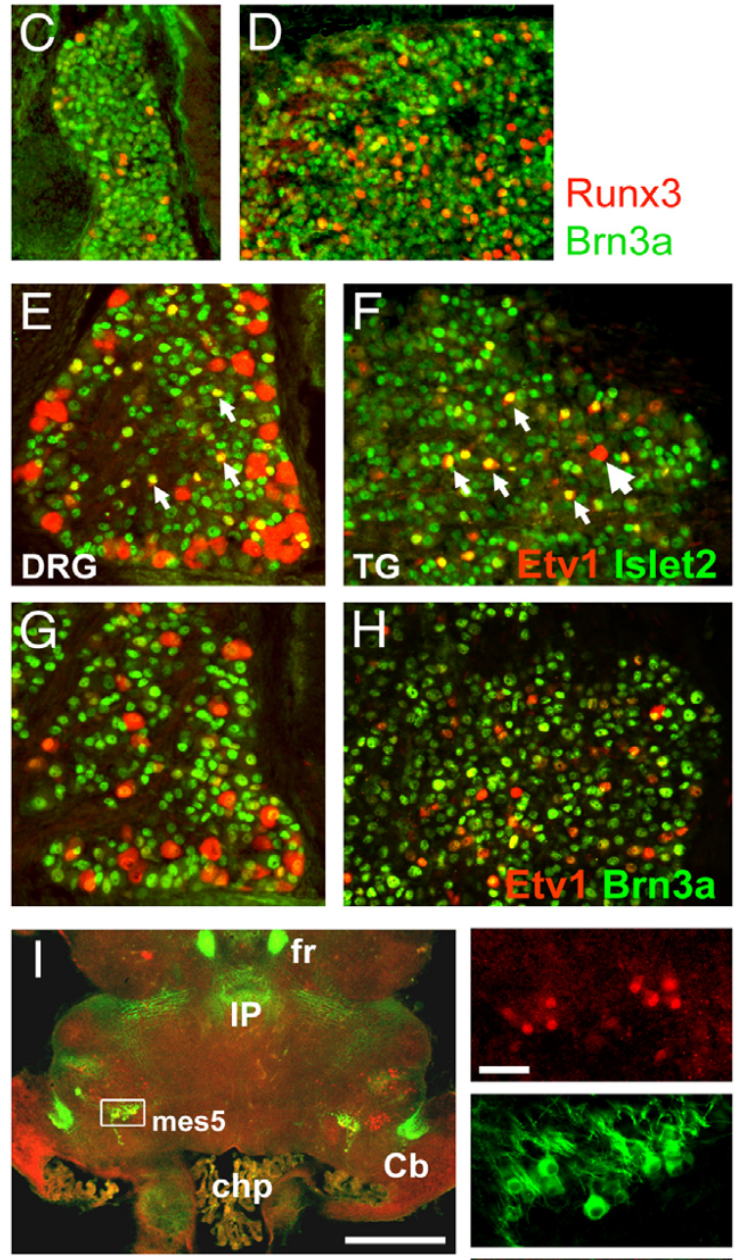

Etv1 Brn3a-LacZ

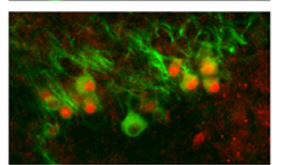

\section{Figure 2}

Selective expression of proprioceptor markers in the DRG and trigeminal system. The sensory ganglia of wild-type embryos were examined at EI3.5 and EI6.5 for the expression of transcription factors Brn3a, EtvI, Runx3 and Islet2. (a-d) At EI3.5, Etvl expression is restricted to the DRG, while Runx3 is expressed in both the DRG and TG. (e-h) At EI6.5, Etvl is expressed in both the DRG and the TG, but in the TG Etvl positive neurons with large nuclei consistent with la proprioceptors are rare (large arrow). Instead, the majority of EtvI-positive neurons in the TG have nuclei of intermediate size and coexpress Islet2; similar cells are also found in the DRG (small arrows). The la proprioceptors of the DRG co-express Brn3a, but at relatively low levels. (i) Etv I expression in the mesV of an EI8.5 embryo expressing a tauLacZ transgene integrated into the Brn3a locus [42], which is thus heterozygous for Brn3a, but phenotypically normal. Numerous neurons that co-express Etvl and the Brn3a-LacZ marker are noted. The caudal location and large size of these neurons are consistent with proprioceptors innervating the muscles of mastication. $\mathrm{Cb}$, cerebellum; chp, choroid plexus; fr, fasciculus retroflexus; IP, interpeduncular nucleus; mes5, mesencephalic trigeminal. Scale $50 \mu \mathrm{m}(\mathrm{a}-\mathrm{h}), 400 \mu \mathrm{m}$ (i), $50 \mu \mathrm{m}$ (i, inset). 
Table 2: Increased transcripts in the DRG of Brn3a knockout mouse

\begin{tabular}{|c|c|c|c|c|c|c|}
\hline Transcript & Symbol & Class & WT & HT & $\mathrm{KO}$ & KO/WT \\
\hline Chordin-like I & ChrdlI & Dev & 5 & 2 & 134 & 27.4 \\
\hline Musculin (MyoR) & Msc & TX & 211 & 675 & 1,260 & 6.0 \\
\hline Insulinoma-associated I & $\left.\operatorname{lnsm}\right|^{2}$ & TX & 153 & 301 & 827 & 5.4 \\
\hline GABA transporter I (Gabtl) & Slc6al & NT & 74 & 93 & 397 & 5.3 \\
\hline Microfibrillar-associated 4 & Mfap4 & Unk & 112 & 370 & 559 & 5.0 \\
\hline Secretogranin II & Scg2 & SY & 206 & 253 & 966 & 4.7 \\
\hline C-fos induced growth factor (VEGF-D) & Figf & Dev & 76 & 102 & 319 & 4.2 \\
\hline Guanylate cyclase I, alpha 3 & Gucyla3 & ST & 50 & 82 & 205 & 4.1 \\
\hline Neurogenic differentiation 6 (Math2, Nex) & Neurod6 & TX & 83 & 200 & 344 & 4.1 \\
\hline Somatostatin & Sst & NT & 215 & 382 & 830 & 3.9 \\
\hline Neurexin III & $\mathrm{Nrxn} 3^{4}$ & SY & 367 & 961 & 1,412 & 3.8 \\
\hline Bruno-like 4 & Brunol433 & Other & 154 & 274 & 588 & 3.8 \\
\hline Cell adhesion molecule with homology to LICAM & Chll & $A X$ & 128 & 127 & 466 & 3.6 \\
\hline Junctophilin I & JphI & Other & 74 & 119 & 262 & 3.5 \\
\hline Glutamate receptor, ionotropic, AMPA4 & Gria433 & NT & 46 & 80 & 161 & 3.5 \\
\hline Glutamate receptor, ionotropic, AMPA3 & Gria3 & NT & 40 & 66 & 138 & 3.5 \\
\hline Zinc finger homeobox Ib & Zfhxlb ${ }^{2}$ & TX & 81 & 127 & 270 & 3.3 \\
\hline Nel-like 2 & Nell2 & $A X$ & 383 & 331 & 1,215 & 3.2 \\
\hline Follistatin-like 5 & Fstl52 & Dev & 281 & 389 & 885 & 3.2 \\
\hline Disabled homolog I & $\left.\mathrm{Dab}\right|^{2}$ & $A X$ & 90 & 42 & 272 & 3.0 \\
\hline Mannan-binding lectin serine protease I & Maspl & Other & 95 & 101 & 282 & 3.0 \\
\hline \multicolumn{7}{|l|}{ Selected } \\
\hline Semaphorin $3 C$ & Sema $3 c^{2}$ & $A X$ & 589 & 723 & $\mathrm{I}, 732$ & 2.9 \\
\hline Cholecystokinin A receptor & Cckar & NT & 95 & 161 & 269 & 2.8 \\
\hline Serotonin receptor $3 \mathrm{~A}$ & $\mathrm{Htr} 3 \mathrm{a}$ & NT & 778 & 1,160 & 2,090 & 2.7 \\
\hline Homeobox A5 & Hoxa5 & TX & 628 & 896 & $\mathrm{I}, 493$ & 2.4 \\
\hline Neurogenic differentiation I & Neurod ${ }^{2}$ & $\mathrm{TX}$ & 1,048 & 1,468 & 2,440 & 2.3 \\
\hline p21-activated kinase 3 & Pak32 & SY & 246 & 270 & 568 & 2.3 \\
\hline Semaphorin 3D & Sema3d & $A X$ & 318 & 365 & 725 & 2.3 \\
\hline Protocadherin 17 & PcdhI72 & $A X$ & 331 & 340 & 746 & 2.3 \\
\hline Spondin I, (f-spondin) & Spon I & $A X$ & 629 & 778 & $1,4 \mid 3$ & 2.2 \\
\hline $\mathrm{K}^{+}$voltage-gated channel, Isk family & Kcnell & NT & 613 & 813 & 1,328 & 2.2 \\
\hline Deleted in colorectal carcinoma & Dcc & $A X$ & 93 & 101 & 200 & 2.2 \\
\hline Netrin GI & Ntngl & $A X$ & 388 & 556 & 812 & 2.1 \\
\hline Neuropilin 2 & Nrp2 & $A X$ & 509 & 485 & 1,063 & 2.1 \\
\hline Cadherin 22 & Cdh22 & $A X$ & 199 & 226 & 414 & 2.1 \\
\hline Synapsin II & Syn $2^{4}$ & SY & 643 & 688 & 1,324 & 2.1 \\
\hline Glutamate receptor, ionotropic, kainate I & Grik I & NT & 221 & 241 & 455 & 2.1 \\
\hline Protocadherin 8 & Pcdh8 ${ }^{2}$ & $A X$ & 278 & 398 & 569 & 2.0 \\
\hline GDNF receptor alpha 2 & Gfra2 & Dev & 363 & 436 & 735 & 2.0 \\
\hline Nescient helix loop helix 2 (Nscl2) & Nhlh2 & TX & $\mathrm{I}, 222$ & 1,996 & 2,446 & 2.0 \\
\hline
\end{tabular}

Data for one of two independent experiments are shown. All listed transcripts showed increased expression (change $p<0.005$ ) in two independent replicates. Data are complete for all replicated changes above three-fold, and selected data appear for transcripts exhibiting two- to three-fold change. A full data set appears in Additional file I. Superscript numerals represent the number of probe sets concordant for changed expression for a given gene. AX, neurogenesis/axon growth and guidance; Dev, development; KO, knockout; NT, neurotransmission; ST, signal transduction; SY, synapse formation and function; TX, transcription; Unk, unknown; WT, wild type.

dendrites [24], and Nel-like 2, an epidermal growth factor (EGF)-repeat containing factor with a previously demonstrated role in sensory development [25]. Increased expression was also noted for several molecules with known or likely roles in axon guidance, including Disabled1, Sema3c, Sema3d, f-spondin, Cadherin22, Protocadherin 8, Protocadherin 17, Dcc, and NetrinG1. Decreased expression was noted for advillin, an actin binding protein that is a known mediator of sensory neu- rite outgrowth [26], as well as Ncam2 and Eph receptor A7. These changes suggest that the profound defects observed in the sensory axons of Brn3a null mice [17] result from the derangement of a coordinated program of expression of mediators of axon growth and guidance, rather than from a single molecular lesion.

Loss of Brn3a also resulted in significant changes in the expression of other transcription factors. Notably, dele- 
Table 3: Transcripts decreased in the DRG of Brn3a null mice

\begin{tabular}{|c|c|c|c|c|c|c|}
\hline Transcript & Symbol & Class & WT & $\mathrm{HT}$ & $\mathrm{KO}$ & WT/KO \\
\hline Limb expression I & Lixl & Unk & 984 & 923 & 46 & 21.4 \\
\hline Vascular endothelial growth factor $\mathrm{C}$ & Vegfc & Dev & 55 & 54 & 3 & 16.1 \\
\hline Neural cell adhesion molecule 2 & Ncam $2^{2}$ & $\mathrm{AX}$ & 280 & 212 & 22 & 12.9 \\
\hline Runt related 3 & Runx3 & $\mathrm{TX}$ & 251 & 421 & 22 & 11.3 \\
\hline Brn3b & Pou4f2 & $\mathrm{TX}$ & 613 & 772 & 61 & 10.0 \\
\hline Brn3a & Pou4f $\left.\right|^{2}$ & $\mathrm{TX}$ & 1,107 & 1,119 & 115 & 9.6 \\
\hline Phospholipase A2, group VII & $\mathrm{Pla} 2 \mathrm{~g} 7$ & ST & 618 & 438 & 77 & 8.1 \\
\hline $\mathrm{K}+$ channel, shaker-related, member I & Kcnal ${ }^{3}$ & NT & 438 & 523 & 59 & 7.4 \\
\hline Advillin & Avil & $A X$ & 2,494 & 1,735 & 364 & 6.9 \\
\hline Galanin & Gal & NT & 5,388 & $4,4 \mid 4$ & 824 & 6.5 \\
\hline Basonuclin I & Bncl & $\mathrm{TX}$ & 875 & 740 & 165 & 5.3 \\
\hline Insulin-like growth factor I & $|g f|^{3}$ & Dev & 820 & 609 & 160 & 5.1 \\
\hline G protein-coupled receptor 64 & Gpr64² & NT & 371 & 298 & 72 & 5.1 \\
\hline Adenylate cyclase activating polypeptide I, PACAP & Adcyapl & NT & 283 & 198 & 57 & 5.0 \\
\hline Regulator of G-protein signaling 10 & Rgs 10 & NT & $\mathrm{I}, 793$ & 1,596 & 362 & 5.0 \\
\hline Parvalbumin & Pvalb & ST & 403 & 223 & 95 & 4.3 \\
\hline $\mathrm{K}+$ channel, shaker-related, beta member 2 & Kcnab2 & NT & 952 & 684 & 238 & 4.0 \\
\hline Diacylglycerol kinase, eta & $\mathrm{Dgkh}^{2}$ & ST & 1,348 & 1,230 & 353 & 3.8 \\
\hline G protein-coupled receptor 73 & Gpr73 & NT & 336 & 157 & 90 & 3.7 \\
\hline Serine proteinase inhibitor, clade A, member 3G; Spi2A & Serpina3g & Other & 426 & 346 & 116 & 3.7 \\
\hline Copine IV & Cpne4 & Unk & 767 & 636 & 216 & 3.6 \\
\hline PQ loop repeat containing I & Pqlcl & Unk & 911 & 596 & 259 & 3.5 \\
\hline Reticulon 4 receptor-like 2; nogo receptor-like 3 & Rtn4rl2 & $A X$ & 789 & 694 & 226 & 3.5 \\
\hline Spermatogenesis associated glutamate-rich protein I & Speer I-ps I & Unk & 349 & 307 & 106 & 3.3 \\
\hline Pappalysin 2 & Pappa2 & Other & 694 & 794 & 225 & 3.1 \\
\hline Brn3c & Pou4f3 & $\mathrm{TX}$ & 394 & 361 & 130 & 3.0 \\
\hline Protein tyrosine phosphatase, receptor type, J & Ptprj & ST & 853 & 918 & 284 & 3.0 \\
\hline Docking protein 4 & Dok4 & ST & 2,014 & 1655 & 679 & 3.0 \\
\hline \multicolumn{7}{|l|}{ Selected } \\
\hline Eph receptor A7 & Epha7 & $A X$ & 206 & 202 & 77 & 2.7 \\
\hline Latexin & $\mathrm{Lxn}$ & NT? & 2,948 & 2,564 & 1,105 & 2.7 \\
\hline DRGII & Prrxll & $\mathrm{TX}$ & $|, 5| 4$ & 1,339 & 569 & 2.7 \\
\hline Protein tyrosine phosphatase, non-receptor type 3 & Ptpn3 & ST & 1,638 & $|, 88|$ & 623 & 2.6 \\
\hline GABA-A receptor, subunit alpha 2 & Gabra2 & NT & 62 & 90 & 24 & 2.6 \\
\hline $\mathrm{Na}+$ channel, type VII, alpha & $\operatorname{Scn} 7 \mathrm{a}$ & NT & 1,199 & 1,386 & 506 & 2.4 \\
\hline Protein tyrosine phosphatase, receptor type, $R$ & Ptprr & ST & 3,376 & 3,207 & 1,467 & 2.3 \\
\hline Rap I, GTPase-activating protein I & Raplgal & ST & $|, 72|$ & 1,686 & 749 & 2.3 \\
\hline LIM domain binding 2 & Ldb2 & $\mathrm{TX}$ & 794 & 492 & 349 & 2.3 \\
\hline Anthrax toxin receptor 2 & Antxr2 & Unk & 1,355 & 1,095 & 608 & 2.2 \\
\hline Runt related txn factor I & Runxl & $\mathrm{TX}$ & 360 & 343 & 162 & 2.2 \\
\hline Homeobox DI & Hoxd I & $\mathrm{TX}$ & 852 & 751 & 404 & 2.1 \\
\hline Inhibitor of DNA binding I & Id I & $\mathrm{TX}$ & I,248 & $\mathrm{I}, 05 \mathrm{I}$ & 624 & 2.0 \\
\hline
\end{tabular}

All listed transcripts showed decreased expression (change $p>0.995$ ) in two independent replicates. Complete data appear for all replicated changes above three-fold, and selected data appear for transcripts exhibiting change in the two- to three-fold range. A full data set appears in Additional File 2. Note that Brn3a transcripts are still detected in the Brn3a null genotype, consistent with the detection of the 3'-end of residual non-coding transcripts. AX, neurogenesis/axon growth and guidance; Dev, development; KO, knockout; NT, neurotransmission; ST, signal transduction; SY, synapse formation and function; TX, transcription; Unk, unknown; WT, wild type.

tion of Brn3a effectively resulted in a triple-knockout of the Pou 4 homeodomain class, because Pou4f2 (Brn3b) expression is nearly eliminated, and Pou $4 \mathrm{f3}$ (Brn3c) expression is greatly reduced in Brn3a knockout ganglia. Marked decreases were also observed in specific markers of sensory neuron subclasses, including Prrxl1/DRG11, Runx1 and Runx3. In contrast, specific bHLH genes, including those encoding NeuroD1, NeuroD6, Msc, and Nhlh2, were increased, and, perhaps consistent with this, the inhibitory bHLH factor Id1, which can act to oppose the action of neurogenic bHLH genes, was decreased. The significance of some of these changes in the hierarchy of gene regulation in developing sensory neurons is discussed below.

Loss of Brn3a expression resulted in increased expression of essentially all of the anterior $\operatorname{Hox} A, \operatorname{Hox} B$ and $\operatorname{Hox} C$ genes, and the changes reached statistical significance $(p<$ 


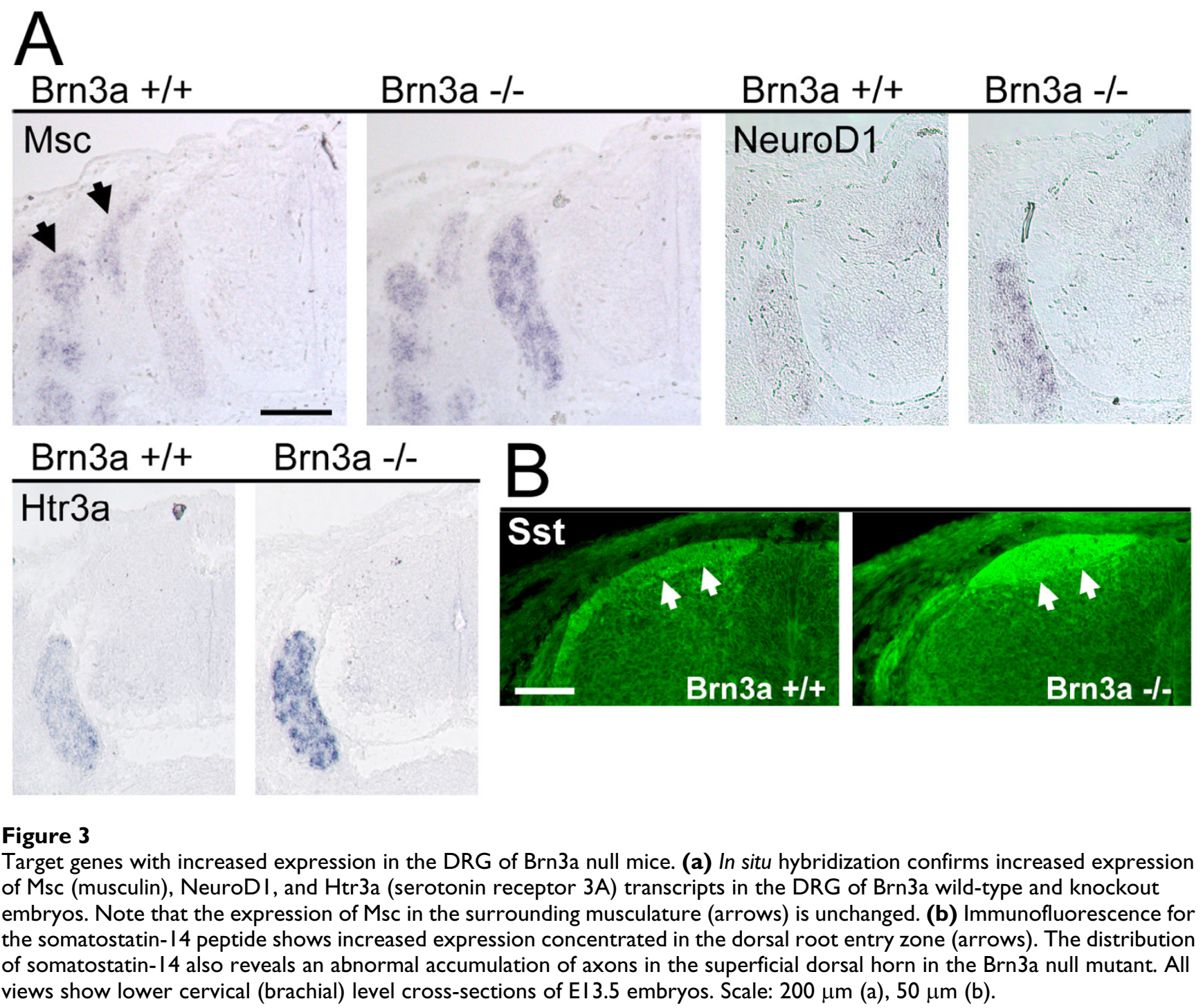

0.005 or $p>0.995$, Materials and Methods) for seven genes in this group (Figure 5). The posterior Hox genes were expressed at much lower levels than the anterior factors, as expected for brachial-level DRG, and exhibited either unchanged or decreased expression in the knockout. Members of the HoxD cluster were not significantly expressed in the DRG (data not shown), with the exception of HoxD1, which, unlike the other anterior Hox gene products, exhibited decreased expression in Brn3a null DRG, and was also the only Hox gene product expressed at significant levels in the TG (see additional file 3) [20].

In prior studies, we have shown that Brn3a regulates its own expression via direct negative feedback, and that, in heterozygous Brn3a knockout mice, partial relief of this negative autoregulation results in increased expression of the intact allele, resulting in nearly complete gene dosage compensation. To determine whether gene dosage compensation is also present at spinal levels, we examined the levels of all increased and decreased transcripts in $\mathrm{Brn}_{3} \mathrm{a}^{+}$ ,$+ \mathrm{Brn} \mathrm{a}^{+/-}$and $\mathrm{Brn} 3 \mathrm{a}^{-/}$ganglia (see additional files 2 and 4 ). In each case, the mean effect of the loss of one Brn3a allele on target gene expression was $16 \%$ to $19 \%$ of the effect of the loss of both alleles, compared to the $50 \%$ change that would be expected without any compensatory mechanism, indicating significant but incomplete compensation for gene dosage.

\section{A subset of Brn3a targets are unique to the cranial sensory ganglia}

Comparison of the regulatory targets of Brn3a in the developing DRG with our prior analysis of the TG [20] suggests that there are many downstream genes in common between these ganglia. However, results from the 


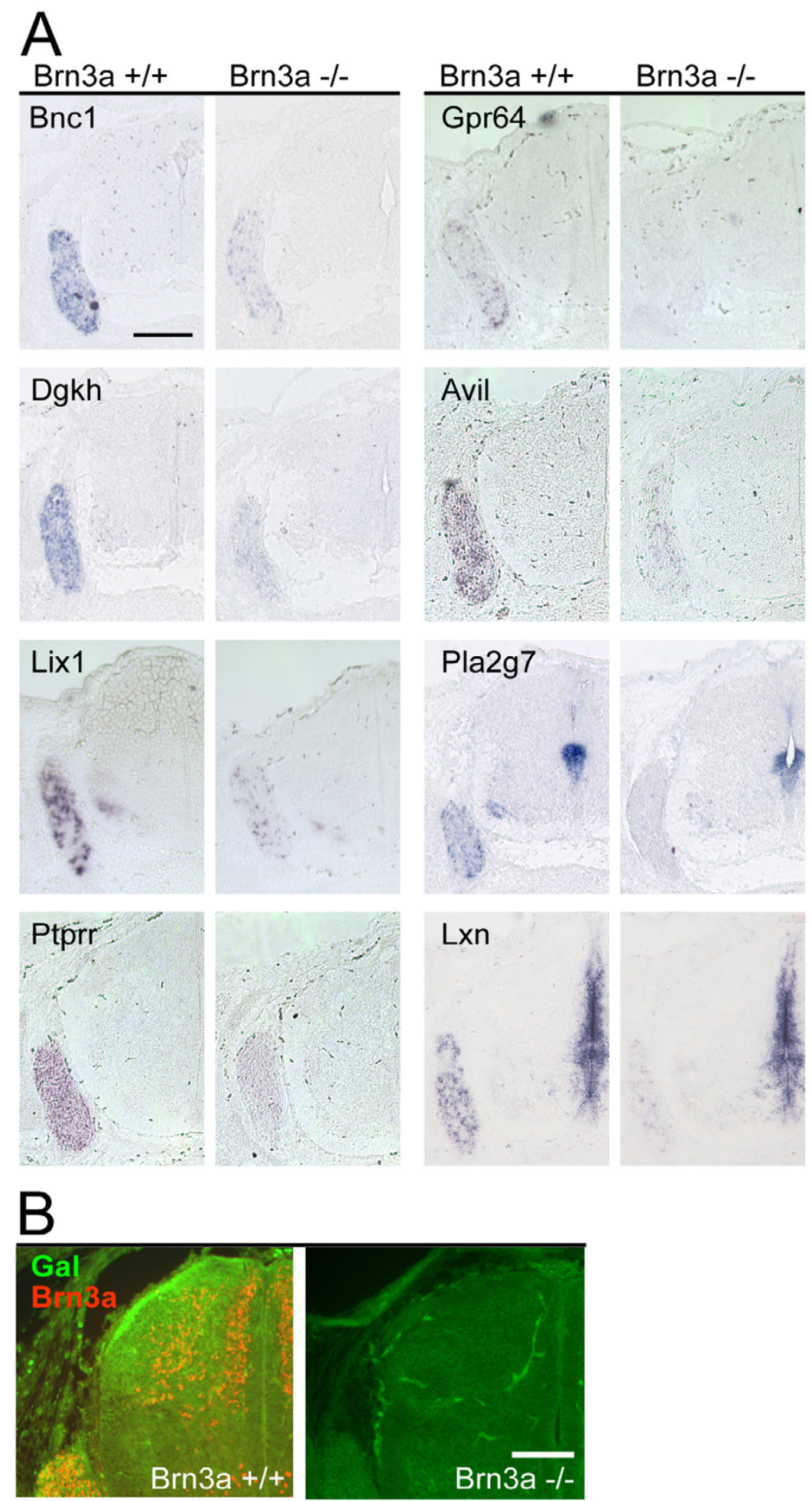

\section{Figure 4}

Target genes with decreased expression in the DRG of Brn3a null mice. (a) In situ hybridization confirms decreased expression of multiple Brn3a downstream targets. (b) Immunofluorescence for the galanin neuropeptide shows marked reduction in the dorsal horn and dorsal root entry zone of Brn3a null DRG. All views show lower cervical (brachial) level cross sections of EI3.5 embryos. Scale: $200 \mu \mathrm{m}(\mathrm{a}), 100 \mu \mathrm{m}$ (b). 

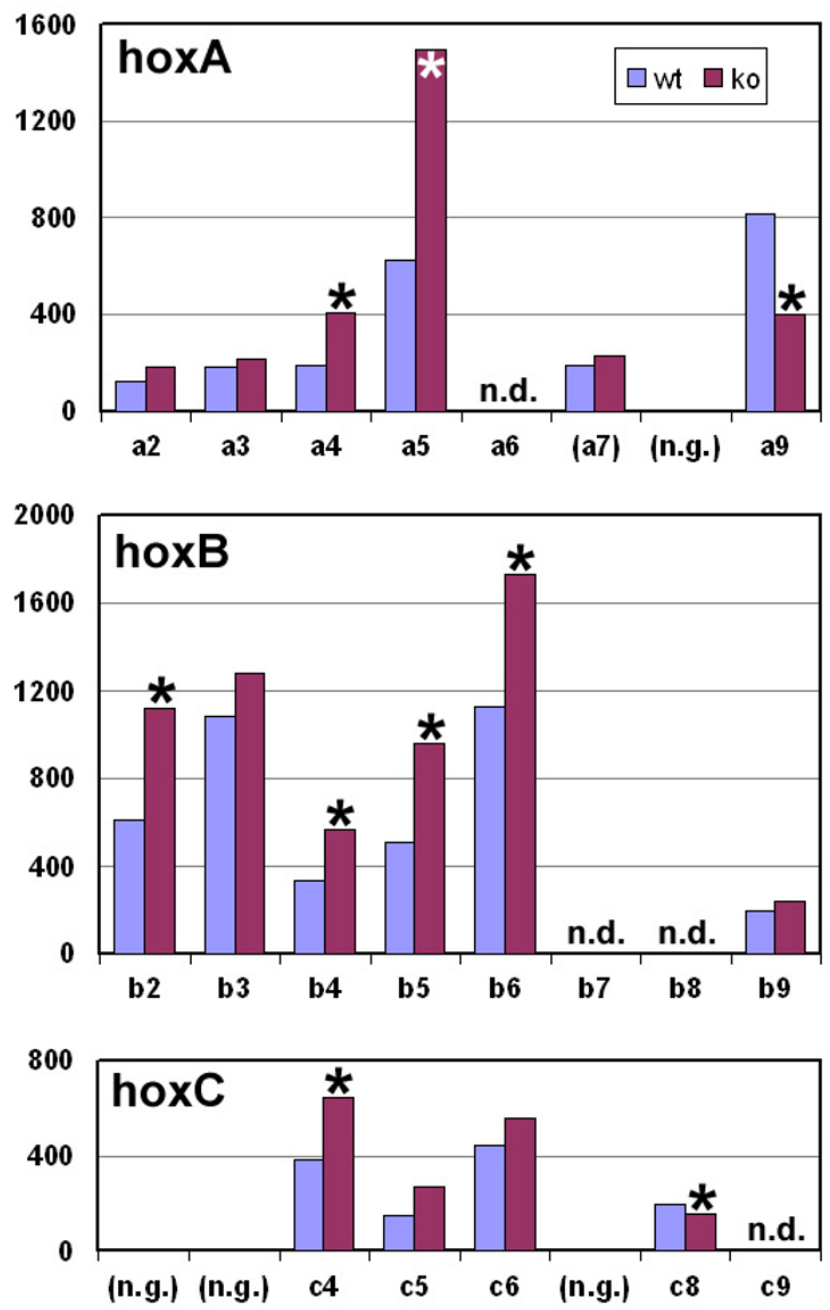

Figure 5

Brn3a regulation of $H o x$ gene expression in the DRG. Hox gene expression data were derived from $430 A+B$ array data for EI3.5 Brn3a wild-type (wt) and knockout (ko) DRG. Statistically significant increases $(p<0.005)$ in the knockout were observed for 7 anterior Hox transcripts, and significant decreases were observed $(p>0.995)$ for two posterior Hox transcripts (asterisks). Similar changes reached statistical significance for 5 anterior Hox genes and one posterior Hox gene in a replicate assay. HoxA7 (parentheses) did not reach statistical significance for detection, indicating high background signal in this probe set. Legend: n.g., no gene at the corresponding position in the cluster; n.d., not determined.

more advanced microarray used in the present study (Affymetrix 430) cannot be compared directly to the prior TG data derived from an older array (Affymetrix U74v2). To make such a comparison, we performed an additional analysis of these E13.5 DRG samples with the U74v2 array. We also updated the interpretation of the results for the TG U74v2 dataset using annotations from Build 34 of the mouse genome. This analysis confirmed that the DRG and TG of E13.5 Brn3a knockout mice have many conserved changes in gene expression (see additional file 3 ). Transcripts increased in both the DRG and TG of Brn3a knockout mice include the bHLH transcription factors musculin and NeuroD1, the neurotransmitters/receptors somatostatin, CCK-receptor A, 5HT-receptor 3A, and GABA-transporter 1, and the growth factor FIGF/VEGF-D. Conserved decreases include the transcription factors Hmx1, Runx1 and basonuclin, the peptides galanin and PACAP, as well as advillin and latexin.

Although the majority of the downstream targets of Brn3a were conserved in the DRG and TG, a subset of genes was uniquely regulated at each axial level. The most profound differences were observed for a set of genes markedly increased in the TG of Brn3a knockout embryos, and unchanged in the DRG (Figure 6). These differentially regulated genes include those encoding the transcription factors Tcfap2b (Ap2 $\beta$ ), NeuroD4 (Math3) and Gata3, the calcium binding protein Calb2 (calretinin) and the small GTP-binding protein Rab3b. These results led us to consider possible mechanisms for cell-specific target gene regulation by Brn3a in these two closely related neural tissues.

The cell-type specific effects of transcription factors are generally attributed to distinct complements of interacting partners, or to the expression of related factors that provide redundancy in some cell types but not in others. However, with the exception of the Hox factors, the very similar gene expression profiles of the DRG and TG do not suggest many candidates for distinct Brn3a partners in these neurons. In addition, the loss of Brn3a effectively eliminates expression of all Pou4 class factors in both the DRG and TG, making selective redundancy unlikely.

One approach to understanding the cell-specific effects of the loss of Brn3a expression is suggested by recent work in which we have demonstrated a correlation between Brn3a binding to its target sites in vivo and $\mathrm{H} 3$-acetylation in the vicinity of the potential binding sites [[27] in press]. Given these results, one potential mechanism for the differential regulation of target genes by Brn3a might be distinct modifications of chromatin at the target gene loci in the DRG and TG, which could modulate the effects of Brn3a or downstream regulatory factors. To examine this question for the differentially regulated loci Tcfap2b, NeuroD4 and Gata3, we used chromatin immunoprecipitation (ChIP) to profile histone $\mathrm{H} 3$ acetylation in wildtype E13.5 DRG and TG (Figure 7). We also examined the Msc locus as an example of a gene that shows similarly increased expression in the DRG and TG of Brn3a knockout mice. ChIP assays of the promoter regions of three constitutively expressed genes, Gapdh, Mapt (tau), and Eno2 (neuron specific enolase), were used as positive con- 

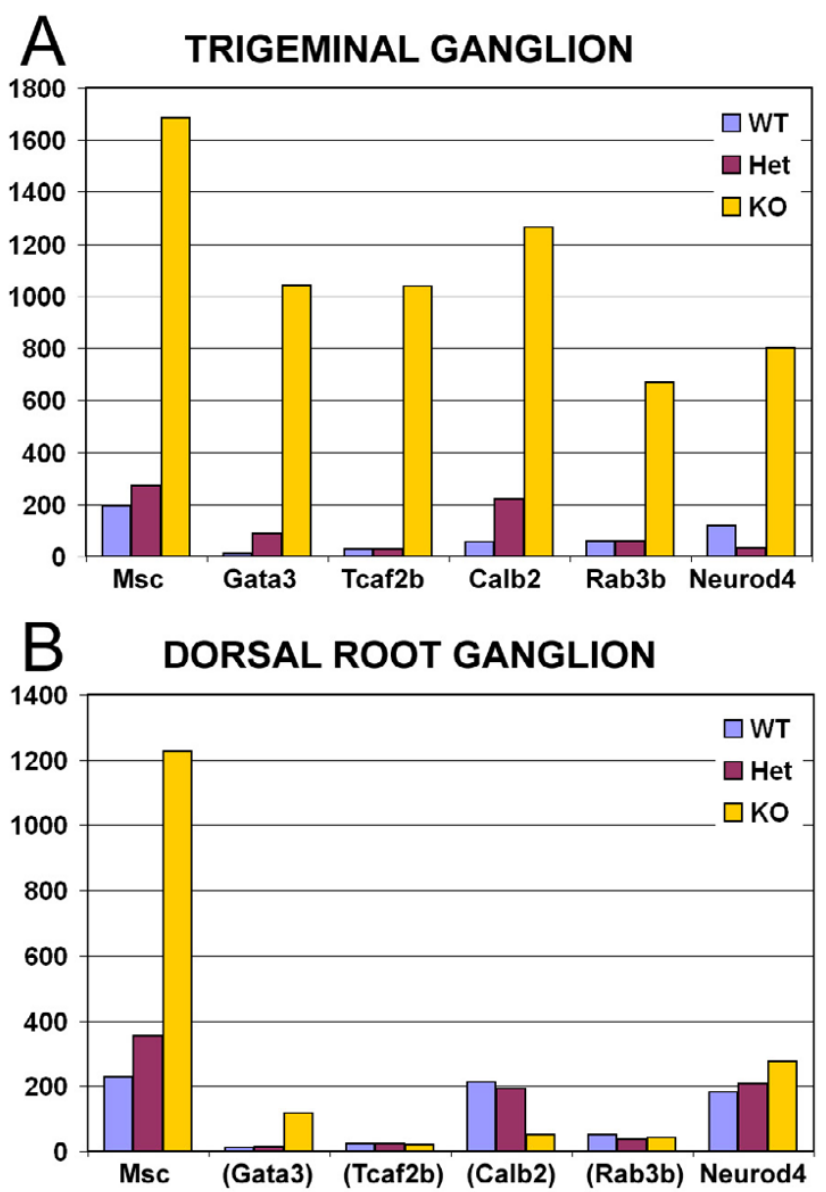

\section{Figure 6}

Trigeminal-specific targets of Brn3a regulation. (a) TG data from a previously published data set [20]. (b) DRG data from the present study. Brn3a wild-type (WT), heterozygote (Het) and knockout (KO) EI3.5 DRG were analyzed for global gene expression using U74Av2+U74v2B arrays to allow direct comparison with the prior analysis of the embryonic TG (Additional file 3). Msc, shown for comparison, exhibits markedly increased expression in the DRG and TG of Brn3a knockout mice, while Gata3, Tcfab2b, Calb2, Rab3b and Neurod4 are increased only in the DRG. Changes in Msc, Gata3, Tcfap2b, Calb2 and NeuroD4 have been previously verified in the TG of Brn3a knockout mice by in situ hybridization or immunofluorescence [20]. Rab3b is newly identified as a Brn3a target in the TG due to progress in the annotation of the mouse genome. Gene abbreviations in parentheses indicate expression below the statistically significant threshold of detection (absent call) in all three genotypes.

trols, and the results were normalized to negative control assays from the promoter region of the Alb1 (albumin) gene, which is not expressed in the nervous system. Because the genomic sequences that regulate these genes in the sensory ganglia have not been defined, we surveyed histone acetylation across these loci using multiple oligo- nucleotide pairs spaced at 500 to 1,000 base-pair (bp) intervals from approximately $-10 \mathrm{~kb}$ to $+15 \mathrm{~kb}$ relative to the start of transcription, using quantitative real-time PCR ('locus-ChIP') ["locus-ChIP", [27] in press].

ChIP profiling of the Msc locus revealed similar levels of H3-acetylation in the DRG and TG. However, ChIP assays of the Tcfap $2 b$ and NeuroD4 loci revealed significantly greater H3-acetylation in the TG relative to the DRG ( $p=$ 0.0003 and $p=0.0005$, respectively), while the Gata3 locus exhibited a trend $(p=0.09)$ toward greater acetylation in the TG. As expected, the positive control promoters were highly acetylated, and the negative control, Alb1, was deacetylated in both the DRG and TG. Thus, the state of $\mathrm{H} 3$-acetylation in wild-type ganglia appears to be correlated both with basal expression and also with a state of latent potential expression that can be induced in Brn3a null ganglia.

\section{Discussion}

Numerous transcription factors have been shown to play key roles in the differentiation of brainstem, spinal, and spinal sensory neurons, yet, for the most part, the programs of gene expression regulated by these factors remain unknown. A layer of complexity is added to the analysis of the downstream targets of these factors by the fact that their expression patterns are often very complex, and may include diverse classes of neurons and non-neuronal cell types with no obvious common characteristics. Brn3a, for example, is expressed in a majority of differentiating peripheral sensory neurons, and also in specific neurons of the spinal cord, olivo-cerebellar system, midbrain, diencephalon and retina. The LIM-domain transcription factor Islet 1 is co-expressed with Brn3a in the sensory system [10], but in the CNS it is expressed primarily in motor neurons $[28,29]$, and also has important roles in the development of the heart [30] and pancreatic islet cells [31]. A fundamental unanswered question is whether these factors, and many others with expression patterns of similar complexity, regulate the same downstream targets in different neuronal types, and in neurons versus non-neuronal cells.

To better understand the molecular pathways of sensory development, we initiated the present study by examining global gene expression in the brachial-level DRG and TG at E13.5. At this stage, when essentially all sensory neurons have exited the cell cycle and markers of sensory subtypes are beginning to be expressed, the gene expression patterns of the DRG and TG are quite similar. Some transcripts exhibit quantitative differences between the ganglia, which may represent relative differences in cellular composition or the timetable of development, but very few transcripts are uniquely expressed in either the DRG or TG. Most prominent among the few transcripts 

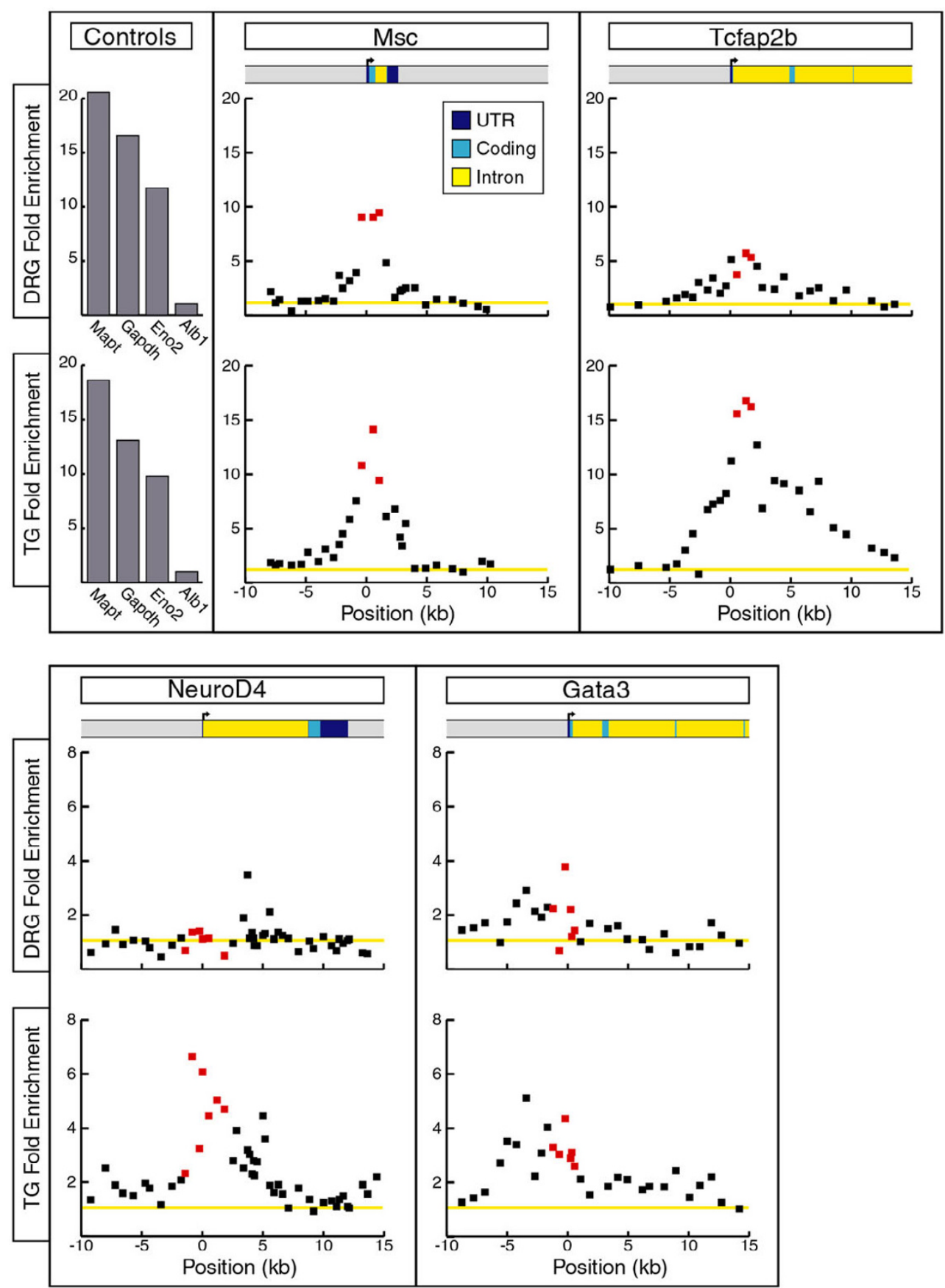

Figure 7

Acetyl-histone $\mathrm{H} 3$ profiling of Brn3a target gene loci. Histone $\mathrm{H} 3$ acetylation was assayed using ChIP and tiled PCR primer pairs from - $10 \mathrm{~kb}$ to $15 \mathrm{~kb}$ of the Msc, Tcfap2b, NeuroD4 and Gata3 gene loci. Positive controls for these assays included primer pairs located in the promoter regions of the Mapt (tau), Gapdh, and Eno2 loci, which are highly expressed in the DRG and TG and are unchanged in Brn3a null mice. The silent alb / locus was used as a negative control and to set the baseline of one-fold enrichment (yellow line). H3 acetylation of these loci in chromatin samples from the EI3.5 DRG and TG were compared by $t$ tests using fold enrichment values for primer pairs flanking the transcription start site of each locus (points shown in red). $\mathrm{H} 3$ acetylation was not significantly different at the msc locus $(p=0.25)$, while Tcfap $2 b(p=0.0003)$ and NeuroD4 ( $p=0.0005)$ showed significantly greater acetylation in the TG, and Gata3 $(p=0.09)$ showed a trend toward greater acetylation in the TG. UTR, untranslated region. 
restricted to a particular axial level are those encoded by the Hox genes and Etv1, which at this stage are expressed only in the DRG. The restriction of the Hox transcripts (with the exception of HoxD1) to spinal levels is expected based on the well characterized axial expression pattern of these genes. Etv1 expression is restricted to the DRG at E13.5 because the first neurons to express this marker, the large proprioceptive neurons innervating muscle spindles, develop within the DRG at spinal levels but at cranial levels are largely sequestered in the mesV. Etv1-expressing neurons that develop in the TG by E16.5 are distinguished by smaller size and the co-expression of Islet2, and appear to represent a distinct subset of sensory neurons.

Global analysis of gene expression in Brn3a knockout and wild-type DRG demonstrates that Brn3a regulates, directly or indirectly, an extensive program of gene expression. Advances in microarray technology and in the annotation of the mouse genome have allowed us to significantly expand the number of identified Brn3a targets from a prior study of the TG [20]. A large number of the downstream targets of Brn3a in the DRG have known roles in neurogenesis or neural function, and include components of axons and synapses, neurotransmitters and their receptors, mediators of intracellular signaling, and transcription factors. Because the regulatory sequences of many of these genes have not been described, in many cases it is not possible to distinguish direct regulatory targets from secondary or compensatory effects. However, in recent studies we have used locus-ChIP to demonstrate that Brn3a is a direct repressor of NeuroD1 and NeuroD4 in the embryonic TG [[27] in press], as well as a negative modulator of its own expression [32,33].

Most Brn3a target genes are conserved between sensory neurons at cranial and spinal levels. However, a subset of genes with the most increased expression in the TG do not change expression in the Brn3a knockout DRG, and are generally undetectable in the E13.5 DRG of animals of any genotype. These differentially regulated transcripts include the transcription factors Tcfap2b, Gata3 and NeuroD4, the calcium binding protein calbindin2 (calretinin), and the small GTP-binding protein Rab3b, implicated in synaptic vesicle release [34]. Because there are normally few transcripts that distinguish the TG from the DRG at this stage of development, the gene expression patterns of the DRG and TG are significantly more different in Brn3a knockout ganglia than in the wild type. This suggests that one important role for Brn3a is to suppress potential differences in gene expression between the spinal and cranial ganglia, mediating a process of 'convergent development' in which functionally similar populations of neurons are generated from different embryological sources.
The state of histone $\mathrm{H} 3$ acetylation of Brn3a target gene loci offers some insight into the underlying mechanism of the differential regulation of these targets at spinal and cranial levels. Normally, H3 acetylation is associated with the regulatory sequences in the promoters of actively transcribed genes. Consistent with this, we have previously shown that the promoter region of Pou4f1 itself is highly acetylated in the TG, and the promoters of genes that are silent in the sensory ganglia regardless of Brn3a genotype are deacetylated [[27] in press]. In wild-type DRG and TG, the differentially regulated genes NeuroD4 and Tcfap $2 b$ are nearly silent, yet these gene loci can be distinguished in trigeminal neurons by increased $\mathrm{H} 3$ acetylation over a region encompassing the transcription start site. The Msc gene is also normally silent, but it exhibits increased expression at both cranial and spinal levels in Brn3a null mice, and is accordingly $\mathrm{H} 3$ acetylated in both the DRG and TG. Thus, in the case of these genes with increased expression in the Brn3a knockout, H3 acetylation appears to reveal a latent state of potential expression, which is normally repressed by Brn3a or its downstream effectors, and de-repressed in Brn3a knockout ganglia.

The failure of DRG neurons to increase NeuroD4 and $T c f a p 2 b$ expression in Brn3a knockout ganglia suggests that a redundant mechanism of repression exists for these genes at spinal but not cranial levels. The action of such a repressor may be reflected in the low levels of histone acetylation at these loci in the DRG. Because the most prominent distinguishing feature of sensory gene expression at spinal levels is the expression of multiple Hox genes, these factors are candidate mediators of this selective repression of NeuroD4 and Tcfap $2 b$ in the DRG. Transcriptional repressor functions have been described for the Hox genes [35], and there is evidence that Hox proteins can directly block the activity of the widely expressed histone acetyltransferase CBP-p300 [36]. Hox gene repression of a subset of Brn3a target gene loci could be an active process at E13.5, or Hox gene expression at earlier developmental stages could produce persisting modifications of chromatin, reflected in the deacetylation of these loci observed here, resulting in reduced transcription even when direct repression by Hox genes is no longer active.

\section{Materials and methods \\ Matings, embryos, and RNA isolation for array analysis}

To generate tissue for microarray analysis, timed matings of Brn3a heterozygote animals were performed, and the embryos were harvested at E13.5. Only embryos corresponding to E13.5 \pm 0.5 days based on the staging system of Theiler [37] were used for microarray analysis. TG were removed by blunt dissection and carefully freed of adherent non-neural tissue with fine forceps. DRG were isolated by stripping of the spinal cord with its adherent ganglia, followed by dissection of the ganglia with fine forceps. 
DRG were harvested from brachial region only, including the C5-T1 levels. Dissected ganglia were placed in RNAse inhibitor solution (RNAlater, Ambion, Austin TX), and RNA was prepared using the RNeasy system (Qiagen, Valencia, CA). Embryos were genotyped for Brn3a alleles as previously described [17] from a sample of tail or hindlimb tissue harvested at the time of ganglion dissection. Genotyped TG or DRG from five embryos were sufficient to provide approximately $5 \mu \mathrm{g}$ of total RNA for a single microarray analysis. The generation of CDNA, production of labeled cRNA, and hybridization to GeneChip arrays were all performed according to standard protocols provided by the manufacturer (Affymetrix, Santa Clara, CA).

\section{Analysis of expression array data}

The principal microarray datasets presented here for the mouse DRG and TG were generated using the Affymetrix $430 \mathrm{~A}$ and $430 \mathrm{~B}$ microarrays. In addition, the same DRG samples were analyzed using Affymetrix U74A and U74B arrays for direct comparison with prior data sets for the TG [20]. The primary analysis of microarray data, including determination of the absence/presence of the assayed transcripts, transcript expression levels, and the probability of change in transcript expression between samples ('change $p$ ') was performed with Microarray Suite 5.0 (Affymetrix). Default Microarray Suite 5.0 parameters were used for increase (I) and decrease (D) calls. For the 430 array set these cutoff values were $p<0.005$ and $p>$ 0.995 for I and D, respectively, and for the U74 arrays, the values were $p<0.003$ and $p>0.997$. All array values were initially scaled to a mean value of 500 using global scaling. To permit more meaningful comparison of the expression levels of transcripts assayed by the 430A and $430 \mathrm{~B}$ arrays, the initial expression values for the 430B array were rescaled based on the expression levels of 100 probe sets in common between the 430A and 430B arrays. Microarray probe sets were related to the corresponding mouse transcripts using the NetAffx database (Affymetrix), based on the NCBI Build 34 annotation of the mouse genome. The array data discussed in this publication have been deposited in NCBI's Gene Expression Omnibus (GEO) [38] and are accessible through GEO series accession number GSE5658.

Comparisons of gene expression between wild-type DRG and TG (Table 1) and between the DRG from Brn3a wildtype, heterozygous, and knockout mice (Tables 2 and 3 ) were performed in duplicate, using separate pools of isolated ganglia. To be included in the tables of changed transcripts for a given tissue or genotype, the following criteria were met: both replicates were called as 'present' in the condition of greater expression; both replicates exhibited an increased or 'I' call for the condition of higher expression; and the probe set identified an annotated and named transcript in NCBI Build 34 of the mouse genome.
Duplicate probe sets identifying the same transcript were eliminated, and the tables are annotated with the number of concordant probe sets for each transcript. Concordance was identified by the agreement of the present and increased calls for the duplicate probe set, and a minimum fold change of 2.0. In the case of multiple concordant probe sets, the probe set with the greatest fold change is listed in the tables. Results for the probe sets meeting the inclusion criteria were ranked by fold change, and the cutoff value for inclusion appears in the tables.

\section{In situ hybridization and immunofluorescence}

Non-isotopic in situ hybridization was performed as previously described [38]. A list of probes used and their sources appears in additional file 5. Immunofluorescence for Brn3a was performed with rabbit polyclonal antisera as previously as previously described [39]. Other antisera used included rabbit antisera against Etv1/Er81 and Runx3 obtained from Dr Sylvia Arber [13,15], and guinea pig antisera against Islet2, obtained from Dr Sam Pfaff [28]. Immunofluorescence for other antigens was performed with commercially available antibodies, including rabbit anti-calretinin (Swant, Bellinzona, Switzerland), rabbit anti-galanin (Bachem, King of Prussia, PA), rabbit anti-somatostatin-14 (Peninsula Laboratories), and goat anti- $\beta$-galactosidase (Biogenesis (MorphoSys), Kingston, $\mathrm{NH})$.

\section{Locus-wide chromatin immunoprecipitation}

Locus-ChIP assays were performed as previously described [[27] in press]. In brief, embryos for ChIP assays were generated from timed matings of ICR mice. DRG and TG were dissected from E13.5 embryos and fixed in 4\% paraformaldehyde for 30 minutes, then quenched with $150 \mathrm{mM}$ glycine. The fixed tissue was washed with phosphate-buffered saline and stored at $-80^{\circ} \mathrm{C}$ until analysis.

Selection of chromatin complexes from embryonic sensory ganglia was performed by a modification of a widely used procedure [40]. For each analysis, fixed ganglia from 30 embryos (60 TG or approximately 300 DRG) were pooled and suspended in lysis buffer containing $50 \mathrm{mM}$ Tris- $\mathrm{HCl}, \mathrm{pH} 8.1$, with $10 \mathrm{mM}$ EDTA and $1 \%$ SDS, $1 \mathrm{mM}$ 4-(2-Aminoethyl)benzenesulfonylfluoride, $\mathrm{HCl}$ (AEBSF) and a proprietary protease inhibitor mix $(1 \times$ Complete Mini, Roche, Indianapolis, IN; used according to instructions). Chromatin was then fragmented to an average size of 500 bp by sonication, and insoluble cellular debris was removed by centrifugation. The supernatant containing fragmented chromatin was diluted in $15 \mathrm{mM}$ Tris-HCl, pH 8.1, with $150 \mathrm{mM} \mathrm{NaCl}, 1 \mathrm{mM}$ EDTA, $1 \%$ Triton-X$100,0.01 \%$ SDS, and protease inhibitor mix. An unselected ('input') sample of $10 \%$ of the total homogenate was removed prior to antibody selection. 
ChIP was performed using rabbit anti-acetylated histone H3 antibody (Upstate Biotechnology, Inc., Bellerica, MA, catalog no. 06-599), which recognizes histone H3 acetylated at lys 9 and lys 14 . For each selection, $50 \mu \mathrm{g}$ of anti-histone antibody was coupled to $250 \mu \mathrm{L}$ of anti-rabbit IgG magnetic beads (Dynal M-280), in lysis buffer containing $50 \mathrm{mM}$ Tris- $\mathrm{HCl}, \mathrm{pH} 8.1$, with $10 \mathrm{mM}$ EDTA and $1 \%$ SDS. To reduce non-specific background, the chromatin sample was pre-cleared using the magnetic beads with the secondary antibody alone. The sample was then incubated overnight with secondary antibody-coupled beads to select the acetyl H3-containing chromatin complexes. The beads were then washed for 5 minutes at room temperature with each of the following solutions: $20 \mathrm{mM}$ Tris$\mathrm{HCl}, \mathrm{pH}$ 8.1, with $150 \mathrm{mM} \mathrm{NaCl}, 2$ mM EDTA, $0.1 \%$ SDS, and $1 \%$ Triton-X-100; $20 \mathrm{mM}$ Tris- $\mathrm{HCl}, \mathrm{pH} 8.1$, with 500 $\mathrm{mM} \mathrm{NaCl}, 2 \mathrm{mM}$ EDTA, 0.1\% SDS, and 1\% Triton-X-100; $10 \mathrm{mM}$ Tris-HCl, pH 8.1, with $1 \mathrm{mM}$ EDTA, $0.25 \mathrm{M} \mathrm{LiCl}$, $1 \% \mathrm{NP}-40$, and 1\% deoxycholate. Salt and detergent were removed by washing twice with $10 \mathrm{mM}$ Tris- $\mathrm{HCl}, 1 \mathrm{mM}$ EDTA, pH 8. DNA was extracted from the antibody-chromatin complexes and the input sample by heating in 0.1 $\mathrm{M} \mathrm{NaHCO}_{3}$ with $200 \mathrm{mM} \mathrm{NaCl}$ and $1 \%$ SDS at $65^{\circ} \mathrm{C}$ for 4 hours with constant shaking. The input and selected samples were then digested with proteinase $\mathrm{K}$, extracted with phenol/chloroform, and precipitated with ethanol.

\section{Real-time locus-wide PCR analysis}

Chromatin fragments recovered from the immunoprecipitated and input samples were then assayed by real-time PCR using an ABI 7300 thermocycler and SYBR Green fluorimetric detection. To screen an entire gene locus, oligonucleotide pairs were designed at 500 to 1,000 bp intervals throughout the region, and selected and unselected samples were run in parallel in a 96-well plate format. The primer pairs used for locus-ChIP assays of the NeuroD4, Msc, Tcfap2b and Gata3 loci appear in additional file 5.

The enrichment of immunoprecipitated chromatin fragments was assayed by the cycle-threshold difference method [41]. For this method, real-time PCR signals are measured using the 'cycle threshold', or Ct parameter, which is the number of cycles required for the amplification product to reach an arbitrary level of fluorescence intensity (threshold), and is logarithmic to the initial abundance of the target sequence in the sample. For each PCR amplicon, a $\Delta \mathrm{Ct}$ value comparing the unselected (input) and antibody-selected DNA samples was then calculated by subtracting the $\mathrm{Ct}_{\text {selected }}$ from the $\mathrm{Ct}_{\text {input }}$ signal:

$\Delta \mathrm{Ct}=\mathrm{Ct}_{\text {input }}-\mathrm{Ct}_{\text {selected }}$

Fold enrichment values for target sequences bound by the selecting antibodies, corresponding to the y-axis of the
locus-ChIP plots, were calculated using the following equation:

$\mathrm{E}=2^{(\Delta \mathrm{Ct}-\Delta \mathrm{Ctcontrol})}$

Because product formation approximately doubles with each cycle in the linear range of amplification, a $\Delta \mathrm{Ct}$ of one cycle represents a two-fold difference in starting template. A significant advantage of this method is that, for each primer pair, a selected sample is compared directly to its unselected control, which differs only by the antibody selection process. Potentially confounding factors such as small differences in the PCR amplification efficiency of different primer pairs are eliminated in this comparison.

The $\Delta \mathrm{Ct}$ assays for each pool of selected material were normalized to an arbitrary baseline (one-fold enrichment) determined using two primer pairs in the promoter region of the Alb1 (albumin locus), which was chosen as a negative control because it is not transcribed in the nervous system. Fold enrichment values for the Alb1 locus were very similar to values for the unselected, intergenic regions of the target gene loci. Primer pairs in the promoter regions of Mapt (microtubule-associated protein tau) and Eno2 (neuron specific enolase), which exhibit tissue specific expression in the nervous system, and Gapdh (glyceraldehyde-3-phosphate dehydrogenase), which is expressed ubiquitously, were used as positive controls. Comparisons of histone $\mathrm{H} 3$ acetylation at a given locus in the DRG and TG were made using three- to six-fold enrichment values using oligonucleotide pairs in a contiguous genomic region near the transcription start site of the analyzed gene loci. The statistical significance ( $p$ values) of the difference in $\mathrm{H} 3$ acetylation was determined using two-sample, unequal variance $t$-tests.

\section{Competing interests}

The author(s) declare that they have no competing interests.

\section{Additional material}

\section{Additional file 1}

Differential gene expression in trigeminal and dorsal root ganglia. In situ hybridization showing transcripts differentially expressed in the trigeminal and dorsal root ganglia.

Click here for file

[http://www.biomedcentral.com/content/supplementary/1749-

8104-2-3-S1.doc] 


\section{Additional file 2}

Increased and Decreased transcripts in E13.5 DRG of Brn3a knockout mice. This shows a more complete version of the data set presented in Table 1.

Click here for file

[http://www.biomedcentral.com/content/supplementary/1749-

8104-2-3-S2.doc]

\section{Additional file 3}

Direct comparision of altered gene expression in DRG and TG of Brn3a knockout sensory ganglia. Gene expression in the DRG is analyzed using the U74v2 array set to allow direct comparision to a prior data set for the TG.

Click here for file

[http://www.biomedcentral.com/content/supplementary/17498104-2-3-S3.doc]

\section{Additional file 4}

Dorsal root ganglia exhibit significant compensation for the loss of one Brn3a allele. Gene expression levels are compared for Brn3a wild-type, heterozygote, and knockout ganglia to demonstrate the extent to which gene dosage compensation reduces the heterozygote phenotype. Click here for file

[http://www.biomedcentral.com/content/supplementary/17498104-2-3-S4.doc]

\section{Additional file 5}

Summary of insitu hybridization probes andLocus-ChIP oligonucleotides. Summary of insitu hybridization probes andLocus-ChIP oligonucleotides. Click here for file

[http://www.biomedcentral.com/content/supplementary/17498104-2-3-S5.doc]

\section{Acknowledgements}

We would like to acknowledge Bill Wachsman and Lutfunnessa Shireen for assistance with microarray technology. Dr Sylvia Arber generously provided antisera for Runx3 and EtvI/Er8I, and Islet2 antiserum was the generous gift of Dr Sam Pfaff. We would also like to thank Drs Jean-Francois Brunet, Allan Basbaum, Ryoichiro Kageyama, Nobuyuki Itoh, Eric Olson and their associates for in situ hybridization probes. Microarray data used in this study are deposited in the Gene Expression Omnibus, series accession number GSE5658. Supported in part by Department of Veterans Affairs MERIT funding and VISN 22 MIRECC (EET), and NIH awards HD33442 and MH065496. EET and NF are a NARSAD Investigators.

\section{References}

I. Anderson DJ: Lineages and transcription factors in the specification of vertebrate primary sensory neurons. Current Opinion in Neurobiology 1999, 9:517-524.

2. Shirasaki R, Pfaff SL: Transcriptional codes and the control of neuronal identity. Annu Rev Neurosci 2002, 25:25I-28I.

3. Baker CV, Bronner-Fraser M: Vertebrate cranial placodes I. Embryonic induction. Dev Biol 200I, 232:I-6I.

4. Le Douarin NM, Smith J: Development of the peripheral nervous system from the neural crest. Annu Rev Cell Biol 1988, 4:375-404

5. Lazarov NE: Comparative analysis of the chemical neuroanatomy of the mammalian trigeminal ganglion and mesencephalic trigeminal nucleus. Prog Neurobiol 2002, 66:19-59.

6. Hunter E, Begbie J, Mason I, Graham A: Early development of the mesencephalic trigeminal nucleus. Dev Dyn 200I, 222:484-493.
7. Ma Q, Fode C, Guillemot F, Anderson DJ: Neurogenin I and neurogenin2 control two distinct waves of neurogenesis in developing dorsal root ganglia. Genes Dev 1999, 13:1717-1728.

8. Ma $\mathrm{Q}$, Chen Z, Barrantes I, de la Pompa JL, Anderson DL: Neurogenin I is essential for the determination of neuronal precursors for proximal sensory ganglia. Neuron 1998 , 20:469-482.

9. Fode C, Gradwohl G, Morin X, Dierich A, LeMeur M, Goridis C, Guillemot F: The bHLH protein Neurogenin2 is a determination factor for epibranchial placode-derived sensory neurons. Neuron 1998, 20:483-494.

10. Fedtsova N, Perris R, Turner EE: Sonic hedgehog regulates the position of the trigeminal ganglia. Dev Biol 2003, 26I:456-469.

II. Chen ZF, Rebelo S, White F, Malmberg AB, Baba H, Lima D, Woolf C), Basbaum Al, Anderson DJ: The paired homeodomain protein DRGII is required for the projection of cutaneous sensory afferent fibers to the dorsal spinal cord. Neuron 200I, 31:59-73.

12. Chen CL, Broom DC, Liu Y, de Nooij JC, Li Z, Cen C, Samad OA, Jessell TM, Woolf CJ, Ma Q: RunxI Determines Nociceptive Sensory Neuron Phenotype and Is Required for Thermal and Neuropathic Pain. Neuron 2006, 49:365-377.

13. Arber S, Ladle DR, Lin JH, Frank E, Jessell TM: ETS gene Er8 I controls the formation of functional connections between group la sensory afferents and motor neurons. Cell 2000, 101:485-498.

14. Levanon D, Bettoun D, Harris-Cerruti C, Woolf E, Negreanu V, Eilam R, Bernstein Y, Goldenberg D, Xiao C, Fliegauf M, Kremer E, Otto F, Brenner O, Lev-Tov A, Groner Y: The Runx3 transcription factor regulates development and survival of TrkC dorsal root ganglia neurons. Embo J 2002, 21:3454-3463.

15. Kramer I, Sigrist M, de Nooij JC, Taniuchi I, Jessell TM, Arber S: A Role for Runx Transcription Factor Signaling in Dorsal Root Ganglion Sensory Neuron Diversification. Neuron 2006, 49:379-393.

16. McEvilly RJ, Erkman L, Luo L, Sawchenko PE, Ryan AF, Rosenfeld MG: Requirement for Brn-3.0 in differentiation and survival of sensory and motor neurons. Nature 1996, 384:574-577.

17. Eng SR, Gratwick K, Rhee JM, Fedtsova N, Gan L, Turner EE: Defects in sensory axon growth precede neuronal death in Brn3adeficient mice. J Neurosci 200I, 2 I:54I-549.

18. Xiang M, Lin G, Zhou L, Klein WH, Nathans J: Targeted deletion of the mouse POU-domain gene Brn-3a causes a selective loss of neurons in the brainstem and trigeminal ganglion, uncoordinated limb movement, and impaired suckling. Proc Nat Acad Sci 1996, 93: I 1950-I 1955.

19. Huang EJ, Zang K, Schmidt A, Saulys A, Xiang M, Reichardt LF: POU domain factor Brn-3a controls the differentiation and survival of trigeminal neurons by regulating Trk receptor expression. Development 1999, 126:2869-2882.

20. Eng SR, Lanier J, Fedtsova N, Turner EE: Coordinated regulation of gene expression by Brn3a in developing sensory ganglia. Development 2004, I 3 1:3859-3870.

21. Patel TD, Kramer I, Kucera J, Niederkofler V, Jessell TM, Arber S, Snider WD: Peripheral NT3 signaling is required for ETS protein expression and central patterning of proprioceptive sensory afferents. Neuron 2003, 38:403-416.

22. Raappana P, Arvidsson J: Location, morphology, and central projections of mesencephalic trigeminal neurons innervating rat masticatory muscles studied by axonal transport of choleragenoid-horseradish peroxidase. J Comp Neurol 1993, 328: $103-114$

23. Jin M, Ishida M, Katoh-Fukui $Y$, Tsuchiya R, Higashinakagawa T, Ikegami $S$, Arimatsu $Y$ : Reduced pain sensitivity in mice lacking latexin, an inhibitor of metallocarboxypeptidases. Brain Res 2006, 1075: ||7-|2|

24. Demyanenko GP, Schachner M, Anton E, Schmid R, Feng G, Sanes J, Maness PF: Close homolog of LI modulates area-specific neuronal positioning and dendrite orientation in the cerebral cortex. Neuron 2004, 44:423-437.

25. Nelson BR, Claes K, Todd V, Chaverra M, Lefcort F: NELL2 promotes motor and sensory neuron differentiation and stimulates mitogenesis in DRG in vivo. Dev Biol 2004, 270:322-335.

26. Shibata M, Ishii J, Koizumi H, Shibata N, Dohmae N, Takio K, Adachi $H$, Tsujimoto $M$, Arai $H$ : Type $F$ scavenger receptor SREC-I interacts with advillin, a member of the gelsolin/villin family, 
and induces neurite-like outgrowth. I Biol Chem 2004, 279:40084-40090.

27. Lanier J, Quina LA, Eng SR, Cox E, Turner EE: Brn3a target gene recognition in embryonic sensory neurons. Developmental Biology In Press, Accepted Manuscript:.

28. Thaler JP, Koo SJ, Kania A, Lettieri K, Andrews S, Cox C, Jessell TM, Pfaff SL: A postmitotic role for Isl-class LIM homeodomain proteins in the assignment of visceral spinal motor neuron identity. Neuron 2004, 41:337-350.

29. Pfaff SL, Mendelsohn M, Stewart CL, Edlund T, Jessell TM: Requirement for LIM homeobox gene IsII in motor neuron generation reveals a motor neuron-dependent step in interneuron differentiation. Cell 1996, 84:309-320.

30. Cai CL, Liang X, Shi Y, Chu PH, Pfaff SL, Chen J, Evans S: IsII identifies a cardiac progenitor population that proliferates prior to differentiation and contributes a majority of cells to the heart. Dev Cell 2003, 5:877-889.

31. Ahlgren U, Pfaff SL, Jessell TM, Edlund T, Edlund H: Independent requirement for ISLI in formation of pancreatic mesenchyme and islet cells. Nature 1997, 385:257-260.

32. Trieu M, Ma A, Eng SR, Fedtsova N, Turner EE: Direct autoregulation and gene dosage compensation by POU-domain transcription factor Brn3a. Development 2003, I30: | I |-|2|.

33. Trieu M, Rhee JM, Fedtsova N, Turner EE: Autoregulatory sequences are revealed by complex stability screening of the mouse brn-3.0 locus. J Neurosci 1999, 19:6549-6558.

34. Schluter OM, Schmitz F, Jahn R, Rosenmund C, Sudhof TC: A complete genetic analysis of neuronal Rab3 function. J Neurosci 2004, 24:6629-6637.

35. Svingen T, Tonissen KF: Hox transcription factors and their elusive mammalian gene targets. Heredity 2006, 97:88-96.

36. Shen WF, Krishnan K, Lawrence HJ, Largman C: The HOX homeodomain proteins block CBP histone acetyltransferase activity. Mol Cell Biol 200I, 21:7509-7522.

37. Theiler K: The house mouse; development and normal stages from fertilization to 4 weeks of age. Berlin, New York, SpringerVerlag; 1972:168.

38. Birren SJ, Lo L, Anderson DJ: Sympathetic neuroblasts undergo a developmental switch in trophic dependence. Development 1993, II 19:597-610

39. Fedtsova N, Turner EE: Brn-3.0 Expression identifies early postmitotic CNS neurons and sensory neural precursors. Mechanisms of Development 1995, 53:291-304.

40. Luo RX, Postigo AA, Dean DC: Rb interacts with histone deacetylase to repress transcription. Cell 1998, 92:463-473.

4I. Livak KJ, Schmittgen TD: Analysis of relative gene expression data using real-time quantitative PCR and the 2(-Delta Delta C(T)) Method. Methods 200I, 25:402-408.

42. Quina LA, Pak W, Lanier J, Banwait P, Gratwick K, Liu Y, Velasquez T, O'Leary DD, Goulding M, Turner EE: Brn3a-expressing retina ganglion cells project specifically to thalamocortical and collicular visual pathways. J Neurosci 2005, 25: I I595-I I604.

43. Grillet N, Dubreuil V, Dufour HD, Brunet JF: Dynamic expression of RGS4 in the developing nervous system and regulation by the neural type-specific transcription factor Phox2b. J Neurosci 2003, 23:106/3-1062I.

44. Polizzotto MN, Bartlett PF, Turnley AM: Expression of "suppressor of cytokine signalling" (SOCS) genes in the developing and adult mouse nervous system. J Comp Neurol 2000, 423:348-358.
Publish with Bio Med Central and every scientist can read your work free of charge

"BioMed Central will be the most significant development for disseminating the results of biomedical research in our lifetime. "

Sir Paul Nurse, Cancer Research UK

Your research papers will be:

- available free of charge to the entire biomedical community

- peer reviewed and published immediately upon acceptance

- cited in PubMed and archived on PubMed Central

- yours - you keep the copyright
BioMedcentral 